\title{
Cysteinyl Leukotriene Levels in Esophageal Mucosal Biopsies of Children with Eosinophilic Inflammation: Are They All the Same?
}

\author{
Sandeep K. Gupta, M.D., ${ }^{1}$ Marc Peters-Golden, M.D., ${ }^{2}$ Joseph F. Fitzgerald, M.D., ${ }^{1}$ Joseph M. Croffie, M.D., ${ }^{1}$ \\ Marian D. Pfefferkorn, M.D., ${ }^{1}$ Jean P. Molleston, M.D., ${ }^{1}$ Mark R. Corkins, M.D., ${ }^{1}$ and Joel R. Lim, M.D. ${ }^{1}$ \\ ${ }^{1}$ Division of Pediatric Gastroenterology, James Whitcomb Riley Hospital for Children, Indiana University \\ School of Medicine, Indianapolis, Indiana; and ${ }^{2}$ Division of Pulmonary and Critical Care Medicine, University \\ of Michigan Health System, Ann Arbor, Michigan
}

OBJECTIVES: Allergic eosinophilic esophagitis (AEE) is characterized by intense eosinophilic inflammation of the esophageal mucosa. Cysteinyl leukotrienes (CysLT) are eosinophil chemoattractants. We studied CysLT levels in esophageal mucosa of children with AEE and controls.

METHODS: $\quad$ CysLT levels (pg CysLT/ $\mu$ g protein) were quantified by Enzyme-linked Immunosorbent Assay (ELISA) on endoscopically obtained esophageal mucosal biopsies.

RESULTS: $\quad$ Twelve children with AEE (eight boys, mean age $6.6 \mathrm{yr}$, range 1.0-14.5 yr) and 10 controls (six boys, mean age $9.56 \mathrm{yr}$, range 1.08-15.08 yr) were enrolled. None were on anti-LT or corticosteroid therapy. All controls had histologically normal mucosal biopsies of the esophagus, stomach, and duodenum. Patients with AEE had intense eosinophilic inflammation of the esophageal mucosa (mean 39 eosinophils/hpf, range 15-70 eosinophils/hpf) and a normal 24-h pH probe study. CysLT levels were similar between the two groups: mean levels were 12.44 (median 10.87, range 2.54-28.29) in AEE patients and 9.52 (median 9.26, range 1.71-21.64) in controls. CysLT levels did not correlate with the degree of esophageal eosinophilic inflammation. Incidentally, five patients with eosinophilic gastroduodenitis, in addition to esophagitis, were enrolled; their CysLT levels were statistically higher than those of controls.

CONCLUSIONS: This is the first study to examine CysLT levels in esophageal mucosal biopsies of children with AEE and normal children. CysLT levels in AEE patients are similar to those in controls, and independent of the severity of inflammation. While this would argue against the use of CysLT antagonists in the treatment of AEE, further studies into the expression of the CysLT receptor itself are needed.

(Am J Gastroenterol 2006;101:1125-1128)

\section{INTRODUCTION}

Allergic eosinophilic esophagitis (AEE) is an emerging, incompletely understood disease. It is being increasingly encountered in children of all ages and in adults (1-3). The initial descriptions of this entity date back to the 1970s (1) though wider appreciation of this disease occurred in the midto late $1990 \mathrm{~s}$, following the experience of Kelly et al. (2) who fed an elemental diet to 10 children with eosinophilic esophagitis. All 10 patients demonstrated symptomatic response and attenuation of the eosinophilic inflammation.

The diagnostic criteria of AEE are now established and include presence of $\geq 15$ eosinophils/hpf on esophageal mucosal biopsies and absence of pathological gastroesophageal reflux on 24-h continuous monitoring of intraesophageal $\mathrm{pH}$ (4). Vertical lines in the esophageal mucosa, circular rings in the esophagus, and white material adherent to the esophageal mucosa are endoscopic findings highly suggestive of AEE (5, 6). The treatment options for AEE are limited and include corticosteroids (either systemic or topical) and an elemental diet $(2,7-10)$. Patients may suffer disease relapse on discontinuation of therapy $(2,7)$. Long-term use of these therapies is unattractive, as these can be exacting on the patient and families (i.e., elemental diet), or potentially associated with complications (i.e., chronic corticosteroid use). Untreated AEE can progress to esophageal strictures and small-caliber esophagus, in addition to persistence of symptoms. There is an acute need to identify alternate long-term maintenance therapeutic agents that are patient-safe and effective.

Leukotrienes (LTs) are lipid mediators generated from arachidonic acid, a normal constituent of the phospholipid bilayer of biological membranes. Activation of mast cells, eosinophils, and macrophages causes synthesis of cysteinyl leukotrienes (CysLTs) that are proinflammatory mediators 
and eosinophil chemoattractants $(11,12)$. It has been suggested that anti-LT agents, such as montelukast, a CysLT receptor antagonist that attenuates airway eosinophilia, may be used to treat AEE (13-15). Levels of CysLT in the esophageal mucosa have, however, not been previously reported.

We hypothesized that elevated CysLT levels in AEE would support the use of CysLT receptor antagonists in the treatment of children with AEE. In this pilot study, we measured the levels of CysLT in esophageal mucosa of children with AEE and controls in order to examine our hypothesis and to generate questions for future research.

\section{METHODS}

\section{Patients}

Patients between the ages of 1 and 18 yr who underwent esophagogastroduodenoscopy through the Division of Pediatric Gastroenterology at the James Whitcomb Riley Hospital for Children, Indiana University School of Medicine, Indianapolis, IN were prospectively considered for the study. We recruited controls (normal endoscopic and histologic appearance of the upper gastrointestinal tract) and patients with AEE (who had $\geq 15$ eosinophils/hpf on esophageal mucosal biopsies with normal biopsies of the gastric and duodenal mucosa).

Two esophageal biopsies were endoscopically obtained for CysLT analysis. These were snap frozen in liquid nitrogen and stored at $-70^{\circ} \mathrm{C}$. The study was approved by the Indiana University/Clarian Health Partners Institutional Review Board and all subjects provided written consent.

\section{CysLT Expression}

Endoscopically obtained esophageal mucosal biopsies were homogenized and lipids were purified using the Sep-pak extraction procedure as previously described (16). CysLT levels, i.e., LTC4, LTD4, and LTE4, were quantified using kits obtained from Cayman Chemicals (Ann Arbor, MI). The average of duplicate determinations was calculated and the result expressed as pg CysLT/ $\mu$ g protein for each sample.

\section{Statistical Methods}

The values for each group are expressed as the mean, median, and range. Statistical analysis was performed utilizing SigmaStat software, version 2.03, from SPSS, Inc. (Chicago, IL). Analysis between the two groups for the analytic assays was performed by unpaired 2-tailed Student's $t$-test. A $p$-value of less than 0.05 was considered significant.

\section{RESULTS}

Ten controls (six boys, mean age $9.56 \mathrm{yr}$, median age $9.37 \mathrm{yr}$, range 1.08-15.08 yr) and 12 children with AEE (eight boys, mean age $6.6 \mathrm{yr}$, median age $5.79 \mathrm{yr}$, range $1.0-14.5 \mathrm{yr}$ ) were studied (Table 1). None of the children were on anti-LT or corticosteroid therapy. All controls had histologically normal
Table 1. Clinical Data on Study Patients

\begin{tabular}{|c|c|c|c|}
\hline & $\begin{array}{l}\text { Controls } \\
(\mathrm{N}=10)\end{array}$ & $\begin{array}{c}\text { AEE } \\
(\mathrm{N}=12)\end{array}$ & $\begin{array}{c}\text { EEG } \\
(\mathrm{N}=5)\end{array}$ \\
\hline Mean age (yr) & 9.56 & 6.6 & 7.82 \\
\hline Age range (yr) & $1.08-15.08$ & $81.0-14.5$ & $3.5-13.92$ \\
\hline Male & $6(60 \%)$ & $8(66 \%)$ & $4(80 \%)$ \\
\hline \multicolumn{4}{|l|}{ Symptoms } \\
\hline Vomiting & 2 & 6 & 1 \\
\hline Abdominal pain & 5 & 3 & 1 \\
\hline Dysphagia & 2 & 3 & 1 \\
\hline Eructation & - & - & 1 \\
\hline Heartburn & - & - & 1 \\
\hline \multicolumn{4}{|c|}{ No. of eosinophils, mean (range) } \\
\hline Esophagus & 0 & $39(15-70)$ & $36(20-60)$ \\
\hline Stomach & 0 & 0 & $42(25-60)$ \\
\hline \multicolumn{4}{|l|}{ Allergy data } \\
\hline No. of patients with atopy & 3 & 5 & 3 \\
\hline Allergic rhinitis* & 1 & 2 & 1 \\
\hline Asthma* & 2 & 4 & 2 \\
\hline Eczema* & - & 1 & 1 \\
\hline Family history of atopy & 1 & 3 & 2 \\
\hline Elevated serum IgE level ${ }^{\dagger}$ & $0 / 0$ & $3 / 9$ & $1 / 3$ \\
\hline $\begin{array}{l}\text { Peripheral blood } \\
\text { eosinophilia }{ }^{\dagger}\end{array}$ & $0 / 9$ & $8 / 11$ & $4 / 5$ \\
\hline Skin test positive ${ }^{\dagger}$ & $1 / 1$ & $8 / 9$ & $4 / 5$ \\
\hline
\end{tabular}

* Some patients had $>1$ atopy.

${ }^{\dagger}$ Both the denominator and numerator are reported as not all patients had all studies performed.

mucosal biopsies of the esophagus, stomach, and duodenum. Patients with AEE had intense eosinophilic inflammation of the esophageal mucosa (mean 39 eosinophils/hpf, range 1570 eosinophils/hpf), histologically normal gastric and duodenal mucosal biopsies, and an absence of pathologic gastroesophageal reflux on 24-h $\mathrm{pH}$ probe study.

CysLT levels were measured in esophageal mucosal biopsies and were similar between controls and AEE patients. The mean CysLT levels (pg CysLT/ $\mu$ g protein) were 9.52 (median 9.26, range 1.71-21.64) in controls and 12.44 (median 10.87, range 2.54-28.29) in AEE patients $(p=0.56)$. CysLT levels did not correlate with the degree of esophageal eosinophilic inflammation.

During the course of this prospective study, we had five patients (four boys, mean age $7.82 \mathrm{yr}$, median age $8.42 \mathrm{yr}$, range 3.5-13.92 yr) whose biopsies revealed more widespread inflammation of the upper gastrointestinal tract. All five patients had intense eosinophilic esophagitis and concomitant moderate-to-severe eosinophilic gastritis/ duodenitis, and were grouped as "eosinophilic esophagogastroduodenitis (EEG)." None of the patients were on antiLT therapy. They each had intense eosinophilic inflammation of the esophageal mucosa (mean 36 eosinophils/hpf, range 20-60 eosinophils/hpf) and moderate-to-severe eosinophilic gastritis; two of the four patients had moderate eosinophilic duodenitis. All had an absence of pathologic gastroesophageal reflux on 24-h pH probe study. Mean CysLT levels in the esophageal mucosal biopsies of EEG patients were 33.62 (median 23.61, range 2.54-96.94); these were significantly different from CysLT levels in controls $(p=0.016)$. 


\section{DISCUSSION}

In this study we measured the levels of CysLT in esophageal mucosal biopsies in order to examine the role of LT in the pathogenesis of AEE. LT are 5-lipoxygenase metabolites of the 20-carbon unsaturated fatty acid arachidonic acid produced by various cells, including mast cells, macrophages, and eosinophils $(11,12)$. The 5-lipoxygenase pathway forms two classes of LT, the nonpeptide LT, namely LTB4, and the CysLT, namely LTC4, LTD4, and LTE4. LTC4 is actively transported extracellularly where subsequent cleavage of amino acids yields LTD4 and LTE4. CysLTs activate CysLT receptors 1 and 2 (CysLT1 and CysLT2) and generate the various biological effects associated with CysLT (17).

CysLTs are proinflammatory mediators and eosinophil chemoattractants. They inhibit apoptosis and promote eosinophil survival. Inhalation of LTD4 increases airway eosinophils in asthmatics via a putative direct chemotactic effect on eosinophils (12). CysLT expression is upregulated in asthmatics and in infants with bronchopulmonary dysplasia and cystic fibrosis (12). LTD4, an extremely potent eosinophil chemoattractant, is thought to also be released from eosinophils within the gut wall. This dual action helps it perpetuate and sustain eosinophilic inflammation (18). CysLT1 receptor antagonists, like montelukast, zafirlukast, and pranlukast, attenuate the number of eosinophils present in the airway, sputum, and peripheral blood of asthmatics, suppress the release of inflammatory mediators, and diminish further recruitment of proinflammatory cells (19-21). These drugs are widely and safely used in the treatment of asthma $(19,22)$.

Montelukast has been reported to benefit patients with eosinophilic inflammation of the gastrointestinal tract, but the data are incomplete/unclear. In a recent report, montelukast was used to symptomatically manage two young adults with eosinophilic gastroenteritis - one had serosal eosinophilic gastroenteritis diagnosed by paracentesis and the other had eosinophilic inflammation on biopsies obtained during colonoscopy $(13,19)$. In another case report, montelukast dramatically reduced peripheral eosinophilia but not mucosal eosinophilia in a patient with eosinophilic gastroenteritis (23).

Vanderhoof et al. (14) recently described the use of montelukast in eight children with eosinophilic inflammation of various parts of the gastrointestinal tract. All eight patients, four of whom had eosinophilic inflammation of the esophagus, had resolution of symptoms within a month of initiation of therapy. It was not reported if any of these patients had endoscopic reevaluation performed. Recently, montelukast was used to treat eight adults with AEE. All patients had a symptomatic response but in none did the eosinophilic inflammation subside on repeat histological studies (15). Friesen et al. (21) reported the use of montelukast in children with duodenal eosinophilia. A symptomatic benefit was noted but repeat endoscopic evaluation was not performed. Anecdotal experience suggests that patients with AEE may be asymptomatic in the face of intense histological abnormalities, and may report symptom resolution/improvement with acid-suppressive therapy without histological improvement (24). These experiences emphasize the inadequacy of subjective end points in meaningfully evaluating the course of this disease. Instead, more objective criteria rather than patient-reported symptom assessment should be employed to assess the efficacy of therapeutic interventions in patients with AEE.

In this pilot study, we did not find a difference in the levels of CysLT between controls and patients with AEE. A number of variables may have negatively affected the findings. The severity of esophageal inflammation may be patchy in AEE patients and may result in sampling error. The number of patients in this pilot study could have contributed to the sampling error. The Enzyme-linked Immunosorbent Assay (ELISA) technique is quantitative and in previous studies in patients with idiopathic pulmonary fibrosis, it has been able to detect 5- to 10-fold differences in CysLT levels in lung tissue compared with controls (25). To minimize the possibility of technique variability, all samples were run as one batch.

Our limited data in a small group of patients with EEG are suggestive of possible overproduction of CysLTs in patients with eosinophilic inflammation that extends beyond the esophagus. This finding might explain why patients with EEG are reported to benefit from CysLT1 receptor antagonists (13, $18,21,23)$. While this requires more definitive exploration in a larger patient sample, it does raise interesting questions about possible distinctions between these disorders. It is plausible that AEE is a distinct disorder from other eosinophilic inflammatory conditions of the gastrointestinal tract, including EEG.

In summary, this is the first study to examine CysLT levels in esophageal mucosal biopsies of children with AEE and normal children. Our results indicate that CysLT expression in AEE patients is similar to that in controls and independent of the severity of inflammation. While this would suggest against the use of CysLT antagonists in the treatment of AEE, it is plausible that a subset of AEE patients may benefit from these drugs. In our ongoing and future studies we intend to study a larger number of patients, both with AEE and with EEG, and examine biopsies of their upper gastrointestinal tracts for the expression of the CysLT receptor itself. We feel it will be worthwhile to perform immunohistochemistry studies on these tissue samples to help identify the cellular source of CysLT. The results may further clarify the utility of this class of drugs in the management of AEE/EEG and also help define the role of mast cells and macrophages in the inflammation associated with AEE/EEG.

\section{ACKNOWLEDGMENTS}

We wish to thank our nurses Libby Mitchell, Gail Waltz, Debbie Horn, Ann Klipsch, Michele Ferrell, Pam Doll, and Marcia Kellner for their diligent efforts in making this study happen, and Lori Heady for expert secretarial assistance. This study was supported by Riley childrens Foundation. 


\section{STUDY HIGHLIGHTS}

\section{What is New Here}

- Allergic eosinophilic esophagitis (AEE) is an emerging and increasingly recognized condition in children and adults.

- Activation of eosinophils induces synthesis of cysteinyl leukotriene (CysLT), promoting inflammation and eosinophil infiltration.

\section{What Is Current Knowledge}

- Cysteinyl leukotriene (CysLT) levels in esophageal mucosa of children with eosinophilic esophagitis are similar to those in controls.

- Children with more wide-spread eosinophilic inflammation of the upper gastrointestinal tract have higher mucosal levels of CysLT than controls.

- CysLT antagonist drugs such as montelukast may not be as efficacious in eosinophilic esophagitis as is hoped.

Reprint requests and correspondence: Sandeep K. Gupta, M.D., Division of Pediatric Gastroenterology, James Whitcomb Riley Hospital for Children, Indiana University School of Medicine, Indianapolis, IN 46202.

Received September 13, 2005; accepted December 18, 2005.

\section{REFERENCES}

1. Levine MS, Saul SH. Idiopathic eosinophilic esophagitis: How common is it? Radiology 1993;186:631-2.

2. Kelly KJ, Lazenby AJ, Rowe PC, et al. Eosinophilic esophagitis attributed to gastroesophageal reflux: Improvement with an amino acid-based formula. Gastroenterology 1995;109:1503-12.

3. Straumann A, Spichtin HP, Grize L, et al. Natural history of primary eosinophilic esophagitis: A follow-up of 30 adult patients for up to 11.5 years. Gastroenterology 2003;125:1660-9.

4. Steiner SJ, Gupta SK, Croffie JM, et al. Correlation between number of eosinophils and reflux index on same day esophageal biopsy and 24-hour $\mathrm{pH}$ monitoring. Am J Gastroenterol 2004;99:801-5.

5. Gupta SK, Fitzgerald JF, Chong SK, et al. Vertical lines in distal esophageal mucosa (VLEM): A true endoscopic manifestation of esophagitis in children? Gastrointest Endosc 1997;45:485-9.

6. Lim JR, Gupta SK, Fitzgerald JF, et al. White specks in esophageal mucosa (WSEM): An endoscopic manifestation of non-reflux eosinophilic esophagitis (EE) in children. Gastrointest Endosc 2004;59:835-8.

7. Liacouras CA, Wenner WJ, Brown K, et al. Primary eosinophilic esophagitis in children: Successful treatment with oral corticosteroids. J Pediatr Gastroenterol Nutr 1998;26:380-5.
8. Faubion WA Jr, Perrault J, Burgart LJ, et al. Treatment of eosinophilic esophagitis with inhaled corticosteroids. J Pediatr Gastroenterol Nutr 1998;27:90-3.

9. Gupta SK, Fitzgerald JF, Davis MM, et al. Treatment of allergic eosinophilic esophagitis (AEE) with oral prednisone (P) and swallowed fluticasone (F): A randomized, prospective study in children. Gastroenterology 2003;124:A19.

10. Markowitz JE, Spergel JM, Ruchelli E, et al. Elemental diet is an effective treatment for eosinophilic esophagitis in children and adolescents. Am J Gastroenterol 2003;98:77782.

11. Whelan GJ, Blake K, Kissoon N, et al. Effect of montelukast on time-course of exhaled nitric oxide in asthma: Influence of LTC $_{4}$ synthase $\mathrm{A}_{-444} \mathrm{C}$ polymorphism. Pediatr Pulmonol 2003;36:413-20.

12. Bisgaard H. Leukotriene modifiers in pediatric asthma management. Pediatrics 2001;107:381-90.

13. Sing JT Jr, Jones BA. Leukotriene receptor antagonist as a new mode of therapy for eosinophilic gastroenteritis. Am J Gastroenterol 2001;96:S245.

14. Vanderhoof JA, Young RJ, Hanner TL, et al. Montelukast: Use in pediatric patients with eosinophilic gastrointestinal disease. J Pediatr Gastroenterol Nutr 2003;36:293-4.

15. Attwood SEA, Lewis CJ, Bronder CS, et al. Eosinophilic oesophagitis: A novel treatment using montelukast. Gut 2003;52:181-5.

16. Wilborn J, Crofford LJ, Burdick MD, et al. Cultured lung fibroblasts isolated from patients with idiopathic pulmonary fibrosis have a diminished capacity to synthesize prostaglandin E2 and to express cyclooxygenase-2. J Clin Invest 1995;95:1861-8.

17. Salvi SS, Krishna MT, Sampson AP, et al. The antiinflammatory effects of leukotriene-modifying drugs and their use in asthma. Chest 2001;119:1533-46.

18. Schwartz DA, Pardi DS, Murray JA. Use of montelukast as steroid-sparing agent for recurrent eosinophilic gastroenteritis. Dig Dis Sci 2001;46:1787-90.

19. Robinson DS, Campbell D, Barnes PJ. Addition of leukotriene antagonists to therapy in chronic persistent asthma: A randomised double-blind placebo-controlled trial. Lancet 2001;357:2007-11.

20. Smith LJ. Newer asthma therapies. Ann Intern Med 1999; 130:531-2.

21. Friesen CA, Kearns GL, Andre L, et al. Clinical efficacy and pharmacokinetics of montelukast in dyspeptic children with duodenal eosinophilia. J Pediatr Gastroenterol Nutr 2004;38:343-51.

22. Malmstrom K, Rodriguez-Gomez G, Guerra J, et al. Oral montelukast, inhaled beclomethasone, and placebo for chronic asthma. Ann Intern Med 1999;130:487-95.

23. Daikh BE, Ryan CK, Schwartz RH. Montelukast reduces peripheral blood eosinophilia but not tissue eosinophilia or symptoms in a patient with eosinophilic gastroenteritis and esophageal stricture. Ann Allergy Asthma Immunol 2003;90:23-7.

24. Gupta SK, Fitzgerald JF, Chong SKF, et al. Long term outcome of vertical lines in the (distal) esophageal mucosa (VLEM) and eosinophilic esophagitis: A prospective study. Gastrointest Endosc 1996;43:327.

25. Wilborn J, Bailie M, Coffey M, et al. Constitutive activation of 5-lipoxygenase in the lungs of patients with idiopathic pulmonary fibrosis. J Clin Invest 1996;97:1827-36. 